\title{
Superior corrosion resistance spinel-containing sagger material for calcining Li-ion battery cathode material
}

\author{
Maoqi JU' ${ }^{1}$, Yonghe LIANG ${ }^{1 \dagger}$, , Saisai LI ${ }^{1}$, Manfei CAI ${ }^{1}$, Jianhua NIE ${ }^{1}$ and Zhilin SHAN ${ }^{1}$ \\ ${ }^{1}$ The State Key Laboratory of Refractories and Metallurgy, Wuhan University of Science and Technology, \\ Wuhan 430081, China
}

\begin{abstract}
This work addresses the evaluation of different spinel-containing composition sagger material in thermomechanical properties and corrosion resistance contacting with cathode material. In order to improve the corrosion resistance, the efficient way is to prevent the $\mathrm{Li}^{+}$diffusion into the sagger material, $\mathrm{LiAlO}_{2}$ generated by the reaction between spinel and Li-ion battery cathode material wrapped on the surface as corrosion protective layer during the calcination, which prevent the physically contact and react with cathode materials, due to the $\mathrm{LiAlO}_{2}$ obtained the low-activity to react with cathode material. Meanwhile, the thermo-mechanical properties of sagger material with different addition of spinel were characterized. The results indicated that the using of spinel lead to the better mechanical strength and thermal shock resistance of the sagger material due to introducing the second phase and mismatch of thermal expansion, respectively. Considering all the aspects, the optimal addition of spinel was $14 \mathrm{wt} \%$.

(02020 The Ceramic Society of Japan. All rights reserved.
\end{abstract}

Key-words : Sagger material, Cathode material, Spinel, Corrosion resistance

[Received March 11, 2020; Accepted May 10, 2020]

\section{Introduction}

With the popularity of wireless microelectronic devices, lithium-ion batteries (LIB) play an important role in our daily life. $\mathrm{Li}\left(\mathrm{Ni}_{x} \mathrm{Co}_{y} \mathrm{Mn}_{z}\right) \mathrm{O}_{2}$ (LNCM) materials, as the cathode material for LIB, have been widely used worldwide, due to the low-cost, long cyclic life and efficient energy storage. LNCM materials have been usually prepared through high temperature solid-state reactions using $\mathrm{Li}$-, Ni-, Mn- and Co-bearing precursors in the industry. ${ }^{1), 2)}$

Corundum-cordierite saggers are commonly used for preparing of LNCM materials, owing to low thermal expansion, high thermal shock resistance and creep resistance. However, $\mathrm{Li}_{2} \mathrm{O}$ with a strong penetrating ability will be generated during calcination, resulting in $\mathrm{Li}_{2} \mathrm{O}$-bearing compounds formation accompanied with cracks generation, which seriously damage the life of sagger material, especially when the temperature ranged from 900 to $1100{ }^{\circ} \mathrm{C}$. Meanwhile, the spalled sagger material, caused by corrosion reactions, tapped out into LNCM materials, which lead to the contamination of cathode material. The corrosion reactions between sagger material and LNCM material are severe and inevitable. In order to improve the corrosion resistance, the efficient way is to prevent the $\mathrm{Li}^{+}$ diffusion into the sagger material. ${ }^{3)-5)}$

$\mathrm{Mg}-\mathrm{Al}$ spinel, having high melting point and small thermal expansion coefficient, have been proven that could

Corresponding author: Y. Liang; E-mail: wkdlyh@126.com coated on the $\mathrm{LiCoO}_{2}$ to obtain longer cyclic life of LCNM. $^{6-9)}$ It is expected that spinel as sagger refractory composition can exhibit excellent corrosion resistance, which separate effectively sagger material from LNCM material.

Considering these aspects, this article is to elaborate on the properties, including mechanical properties and thermal shock resistance by adding spinel to corundumcordierite material. In particular, the corrosion mechanism between LNCM material and sagger material was presented and the reason was investigated by using Cobearing LIB material as example.

\section{Experimental procedure}

\subsection{Experimental materials}

The raw materials were pre-form spinel (AR78, Zili Corporation Limited, China), cordierite (Hebei, China), tabular alumina (Almatis, China), reactive alumina (Almatis, China), clay (Suzhou, China), lithium carbonate (AR, 99.5\%, Macklin, China) and cobalt carbonate (Macklin, China). The chemical composition of raw material are shown in Table 1.

Table 1. Chemical composition of the raw materials (wt \%)

\begin{tabular}{ccrccccc}
\hline & $\mathrm{Al}_{2} \mathrm{O}_{3}$ & $\mathrm{SiO}_{2}$ & $\mathrm{Fe}_{2} \mathrm{O}_{3}$ & $\mathrm{CaO}$ & $\mathrm{MgO}$ & $\mathrm{K}_{2} \mathrm{O}$ & $\mathrm{Na}_{2} \mathrm{O}$ \\
\hline Spinel & 77.58 & 0.42 & 0.41 & 0.49 & 20.02 & 0.005 & 0.36 \\
Cordierite & 35.73 & 48.09 & 0.80 & 0.46 & 13.78 & 0.22 & 0.03 \\
Corundum & 99.03 & 0.12 & 0.06 & 0.08 & 0.07 & 0.02 & 0.32 \\
\hline
\end{tabular}


Table 2. Compositions of formulas (wt \%)

\begin{tabular}{ccccccc}
\hline Formula & Aggregate & $\begin{array}{c}\text { Cordierite } \\
(1-0 \mathrm{~mm})\end{array}$ & $\begin{array}{c}\text { Corundum } \\
(1-0 \mathrm{~mm})\end{array}$ & $\begin{array}{c}\text { Spinel } \\
(\leq 0.044 \mathrm{~mm})\end{array}$ & $\begin{array}{c}\text { Cordierite } \\
(\leq 0.044 \mathrm{~mm})\end{array}$ & Other powder \\
\hline $0^{\#}$ & 30 & 15 & 18 & 0 & 28 & 9 \\
$1^{\#}$ & 30 & 15 & 18 & 7 & 21 & 9 \\
$2^{\#}$ & 30 & 15 & 18 & 14 & 7 & 9 \\
$3^{\#}$ & 30 & 15 & 18 & 21 & 7 & 9 \\
$4^{\#}$ & 30 & 15 & 18 & 28 & 0 & 9 \\
\hline
\end{tabular}

\subsection{Experiment methods}

Prior to preparation, the powder mixtures were homogenized by ball-milling in ceramic jar with zirconia balls for $2 \mathrm{~h}$ firstly. The preparation process was as follows: all aggregate system components were mixed with half of binder dextrin for $5 \mathrm{~min}$ firstly, and the powder mixtures were added with the rest binder dextrin to further mix for another $5 \mathrm{~min}$. Secondly, the body material was then uniaxially pressed into rectangular bars with the size of $25 \mathrm{~mm} \times 25 \mathrm{~mm} \times 140 \mathrm{~mm}$ at $180 \mathrm{MPa}$. Finally, the samples were dried at $110^{\circ} \mathrm{C}$ for $24 \mathrm{~h}$ after demoulding and then the samples were sintered at $1400^{\circ} \mathrm{C}$ for $3 \mathrm{~h}$ in a muffle. Five compositions were formulated to evaluate the addition of spinel matrix into samples, which were marked as $0^{\#}$ to $4^{\#}$ (Table 2).

The samples used in the static corrosion experiment were cylindrical samples $(\Phi 36 \mathrm{~mm})$, which composed by spinel and cordierite, the matrix of sagger material, and the the composition of spinel in corrosion samples were 100 , $75,50,25$ and $0 \%$. The erode material with the atomic ratio $\mathrm{Li} / \mathrm{Co}=1: 1$ pressed into the same cylindrical shape. Stacking the pre-fired samples and erode materials fired at $1000^{\circ} \mathrm{C}$ for $3 \mathrm{~h}$.

\subsection{Characterization}

The apparent porosity (AP) and bulk density (BD) after firing were measured by the Archimedes method, using water as the immersion liquid, according to GB/T 29972015 and GB/T 5072-2008. The true density was measured by Accupycc 1330 (Micromeritics, Shanghai). Cold modulus of rupture (CMoR) and cold crushing strength (CCS) determined by testing machine (ETM-EX, Microcomputer controlled electronic universal testing machine, Shenzhen Wance Testing Machine Co., Ltd.), according to GB/T 3001-2007. The thermal shock resistance of the samples pre-fired at $1400^{\circ} \mathrm{C}$ was measured by the change in CMoR before and after thermal shock (three cycles of 30 min heating at $1100^{\circ} \mathrm{C}$ and $5 \mathrm{~min}$ of subsequent water quenching), which is the residual strength ratio of CMoR = $\mathrm{CMoR}_{\mathrm{af}} / \mathrm{CMoR}_{\mathrm{be}} * 100 \%$, where $\mathrm{CMoR}_{\mathrm{af}}$ and $\mathrm{CMoR}_{\mathrm{be}}$ represented the CMoR before and after the thermal shock test.

For the corrosion test, the corroded samples were cut, and slag corrosion indexes were measured by the counting pixels method. The corrosion index $I_{\mathrm{c}}$ was calculated by the following equation: $I_{\mathrm{c}}=S_{\mathrm{c}} / S_{\mathrm{o}} * 100 \%, S_{\mathrm{o}}$ was the original section area, $S_{\mathrm{c}}$ was the section area of sample completely react with anode material, which calculated by the ImagePro, a pixel analysis software.
X-ray powder diffraction (XRD) pattern of erosion product were performed on a X'Pert Pro MPD diffractometer (PANalytical, The Netherlands, using Ni filtered). XRD pattern were recorded in the angle range from 7 to $90^{\circ}(2 \theta)$, at a scanning rate of $0.067^{\circ} / \mathrm{s}$. The microstructural characterization of the samples was performed by a scanning electron microscape (SEM, Quanta 400, FEI Company, USA) through back-scattered electron systems fitted with an energy dispersive X-ray spectroscopy.

\section{Results and discussion}

\subsection{Mechanical properties}

Figure 1 shows the AP, BD, CMoR, CCS and permanent linear change (PLC) of samples after heat treatment at $1400^{\circ} \mathrm{C}$ for $3 \mathrm{~h}$. With amount of spinel increased from 0 to $28 \mathrm{wt} \%$, AP of the samples decreased while BD increased [Fig. 1(a)], because of the spinel exhibited higher true density than cordierite (Table 3). With respect to PLC, after firing at $1400^{\circ} \mathrm{C}$, all samples demonstrated shrinkage due to sintering. Besides, the PLC increased significantly with the increasing the amounts of spinel due to the better sinterability of cordierite than spinel [Fig. 1(b)]. ${ }^{10)}$

The CMoR and CCS of samples increased firstly then decreased [Fig. 1(c)], which could be attributed to two major aspects. Firstly, cordierite had smaller strength than spinel, so that introducing of spinel could improve the mechanical strength. Secondly, adding spinel could enhance the mechanical strength due to the development of the toughening mechanisms such as crack defection and bridging. Too much or less addition of spinel could break the balance and influence the toughening mechanism, which result in mechanical strength of samples decreasing. ${ }^{11), 12)}$ It also could be observed from the displacementforce curve [Fig. 1(d)]. The sample with $14 \mathrm{wt} \%$ addition of spinel obtained the most displacement, owing to the toughening mechanism that spinel act as the second phase.

Generally speak, the high temperature mechanical behaviors of the samples are important parameters for their reliability and safety during service. The hot modulus of rupture (HMoR) is often useful in describing the mechanical properties of material at high temperature. Figure 2 showed the HMoR of the samples at $1100^{\circ} \mathrm{C}$. The samples were in high compression due to a large inner temperature gradient at the high temperature and the microcracks in the cooling state between the aggregate and the matrix gradually close during reheating, which led to the increase of HMoR. The sample with $14 \mathrm{wt} \%$ addition of spinel obtained higher elastic modulus at $1100^{\circ} \mathrm{C}$, 

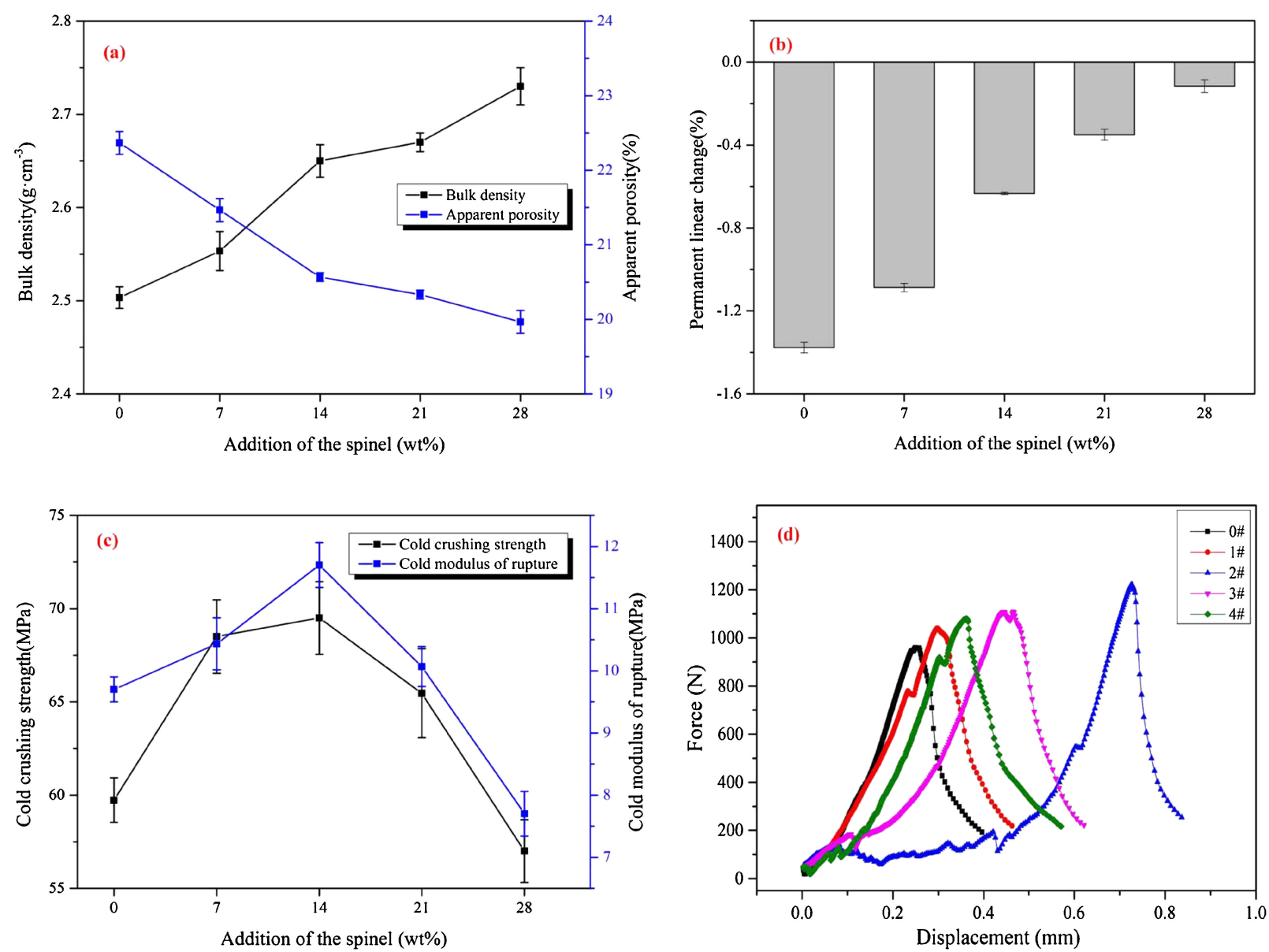

Fig. 1. Physical properties of the samples after firing at $1400^{\circ} \mathrm{C}$. (a) AP and BD, (b) PLC, (c) CMoR and CCS, (d) Displacement-Force curve.

Table 3. The true density of raw materials $\left(\mathrm{g} \cdot \mathrm{cm}^{-1}\right)$

\begin{tabular}{ccc}
\hline & Cordierite & Spinel \\
\hline True density & 2.57 & 3.57 \\
\hline
\end{tabular}

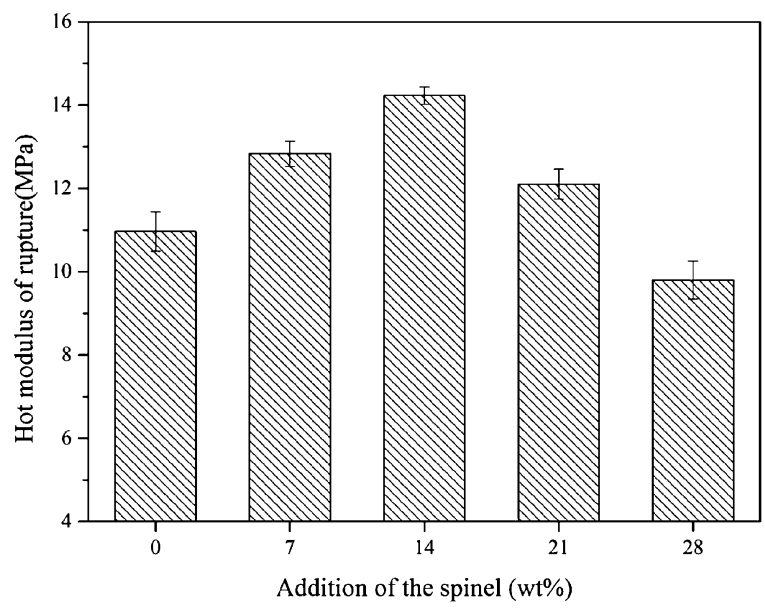

Fig. 2. Hot modulus of rupture of samples.

which might be attribute to the relative density in high temperature and spinel act as the second phase in the materials result in the crack defection. ${ }^{13), 14)}$

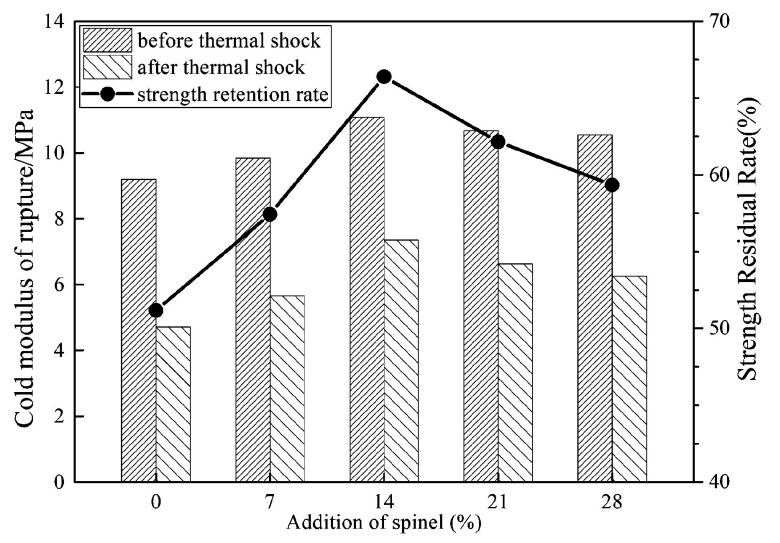

Fig. 3. The residual of properties after three times thermal shock cycle.

\subsection{Thermal shock resistance}

The thermal shock resistance of materials is a comprehensive behavior of mechanical and thermal properties to sagger material. The thermo-mechanical behavior of samples pre-fired at $1400^{\circ} \mathrm{C}$ was characterized by the residual $\mathrm{CMoR}$ after water quenching test for three cycles. Figure 3 showed the results of mechanical properties of samples before and after thermal shock test. It can be observed clearly that CMoR decreased after thermal shock 

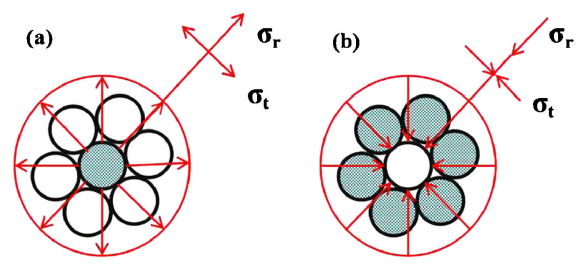

\section{O spinel \\ Cordierite}

Fig. 4. (a) Cordierite surrounding the case of spinel, (b) spinel surrounding the case of cordierite.

test and the sample with $14 \mathrm{wt} \%$ spinel exhibited highest residual CMoR. It could be explained that the onset of inner intiation of cracks and the propagation of subsequent crack during the heating and cooling are responsible for the loss of strength. ${ }^{15), 16)}$

Moreover, the residual rate between samples was also different, which were mainly attributed to the different thermal expansion coefficients between spinel (from $1.7 \times$ $10^{-5} /{ }^{\circ} \mathrm{C}$ to $2.9 \times 10^{-5} /{ }^{\circ} \mathrm{C}$ ) and cordierite (from $2 \times$ $10^{-6} /{ }^{\circ} \mathrm{C}$ to $\left.6 \times 10^{-6} /{ }^{\circ} \mathrm{C}\right),{ }^{17), 18)}$ and making much microcracks during firing. This situation is benefit to improve the thermal shock resistance because of the existance of microcracks from the expansion mismatch between spinel and cordierite. When the addition amounts of spinel was $14 \mathrm{wt} \%$, the spinel was wrapped in the cordierite as shown in Fig. 4(a), because of the lower thermal expansion coefficient of cordierite, and there was a residual compressive stress region around the cordierite and the compressive stress region is smaller than other region, which can result in the bifurcation or deflection of cracks during thermal shock test, thus improving the thermal shock resistance of samples. As the amounts of spinel increased, the probability of spinel being surrounded by another phase decreases, and some spinel agglomerated with each other. Then it is impossible to form an effective compressive region or tensile stress region, and the agglomeration size exceeded the critical size $d_{c}$ leading to matrix cracking and the decrease of thermal shock resistance [Fig. 4(b)]. ${ }^{19)}$ Therefore, when the amounts of spinel too much or too less, the composition tended to be single phase, the probability of producing stress field decreased and the thermal shock resistance of sample decrease.

\subsection{Corrosion resistance}

Figure 5 presented the images of the different compositions samples with 0 to $100 \mathrm{wt} \%$ spinel after corrosion experiments at $1000^{\circ} \mathrm{C}$ for $3 \mathrm{~h}$. It could be observed that all the samples are suffered varying degrees of corrosion except the sample with $100 \%$ spinel. When the amounts of spinel was $75 \mathrm{wt} \%$, only slightly corrosion occurred. However, the corrosion depth increased rapidly from 130 to $570 \mu \mathrm{m}$ with the spinel amounts decreasing. According to the energy-dispersive X-ray spectroscopy as shown in Fig. 6, there is no distribution of Co in the corrosion area, which indicated that the corrosion rate of Li-bearing and Co-bearing compounds to refractories is different, and Libearing compounds are more likely to react with sagger material. It indicated that spinel demonstrated excellent corrosion resistance, which means the spinel could be hard to penetrated by $\mathrm{Li}_{2} \mathrm{O}$. The index of corrosion was calculated according to the Fig. 6 and given in Fig. 7, indicating that the corrosion indexed decreased with the spinel amounts increased.

To figure out the phase of corrosion products, the surface of corrosion layer was removed by file and analyzed by XRD. The XRD patterns of corrosion layer of the prepared cordierite-spinel compositions containing $0-100 \mathrm{wt} \%$ are shown in the Fig. 8. The phase compositions mainly included $\mathrm{LiAlO}_{2}, \mathrm{MgAlO}_{2}, \mathrm{LiAlSiO}_{4}, \mathrm{Li}_{4} \mathrm{SiO}_{4}, \mathrm{MgO}$ and a few of $\mathrm{LiCoO}_{2} \cdot \mathrm{LiAlO}_{2}$ is observed in all samples regardless of spinel addition. Simultaneously, the peak intensity of $\mathrm{LiAlSiO}_{4}$ and $\mathrm{LiSiO}_{4}$ decreased and $\mathrm{LiAlO}_{2}$ increased with the amount of spinel increased. These observations indicated that the corrosion products are $\mathrm{LiAlO}_{2}$, $\mathrm{LiAlSiO}_{4}$ and $\mathrm{Li}_{4} \mathrm{SiO}_{4}$. According to the XRD pattern, the reactions might be occurred between the raw materials and cathode material during firing are as follows. ${ }^{20)}$ Equations (1)-(3) take place in the calcining cathode material and the main corrosion reaction are Eqs. (4) and (5).

$$
\begin{aligned}
& \mathrm{Li}_{2} \mathrm{CO}_{3}==\mathrm{Li}_{2} \mathrm{O}+\mathrm{CO}_{2} \\
& \mathrm{CoCO}_{3}==\mathrm{Co}_{2} \mathrm{O}_{3}+\mathrm{CO}_{2} \\
& \mathrm{Li}_{2} \mathrm{O}+\mathrm{Co}_{2} \mathrm{O}_{3}==\mathrm{LiCoO}_{2} \\
& \mathrm{Li}_{2} \mathrm{O}+\mathrm{MgAl}_{2} \mathrm{O}_{4}==\mathrm{LiAlO}_{2}+\mathrm{MgO} \\
& \mathrm{Li}_{2} \mathrm{O}+2 \mathrm{MgO}_{2} \mathrm{Al}_{2} \mathrm{O}_{3} \cdot 5 \mathrm{SiO}_{2} \\
& \quad==\mathrm{LiAlO}_{2}+\mathrm{Li}_{4} \mathrm{SiO}_{4}+\mathrm{LiAlSiO}_{4}+\mathrm{MgO}
\end{aligned}
$$

In order to further investigate the corrosion mechanism, the un-attacked behavior of spinel is investigated by characterizing the microstructures. As shown in the Figs. 9(a) and $9(\mathrm{~b})$, the sample with $100 \mathrm{wt} \%$ spinel also react with the $\mathrm{Li}_{2} \mathrm{O}$ at contact the interface actually, but it is no significant corrosion phenomenon. And there is a grayappearing protective layer with a thickness of $2-3 \mu \mathrm{m}$ on the surface of white-appearing phase to prevent the further reactions. According to the EDS energy spectrum, it could be inferred that the phase with white-appearing is spinel and the protective layer is $\mathrm{LiAlO}_{2}$ by the atomic ratio (shown in the Table 4). The corrosion area of the sample with $50 \mathrm{wt} \%$ spinel was shown in the Figs. 9(d) and 9(e), it can be found that isolated and dispersed spinel particle with protective layer appeared, and a amount of small grain surround them. As shown in the Figs. 9(f), 9(g) and 9(d), without spinel, cordierite completely react with $\mathrm{Li}_{2} \mathrm{O}$ in the corrosion area, and the reaction layer is mainly composed by particles with size of $3-5 \mu \mathrm{m}$.

Through the above experiment results, it could summarize the schematic of corrosion mechanisms of cordierite and spinel, as shown in Fig. 10. The possible way of cathode material reacted with spinel is as follows [as shown in Fig. 10(a)]: (1) $\mathrm{Li}^{+}$diffused outward from the cathode material during the firing and concentrates on the surface of the spinel; (2) $\mathrm{Li}^{+}$reacted with spinel to generate $\mathrm{LiAlO}_{2}$ [Eq. (4)] and wrapped on the surface of spinel particles to form a reaction layer, which made the reaction difficult to proceed further. Both XRD and SEM results 

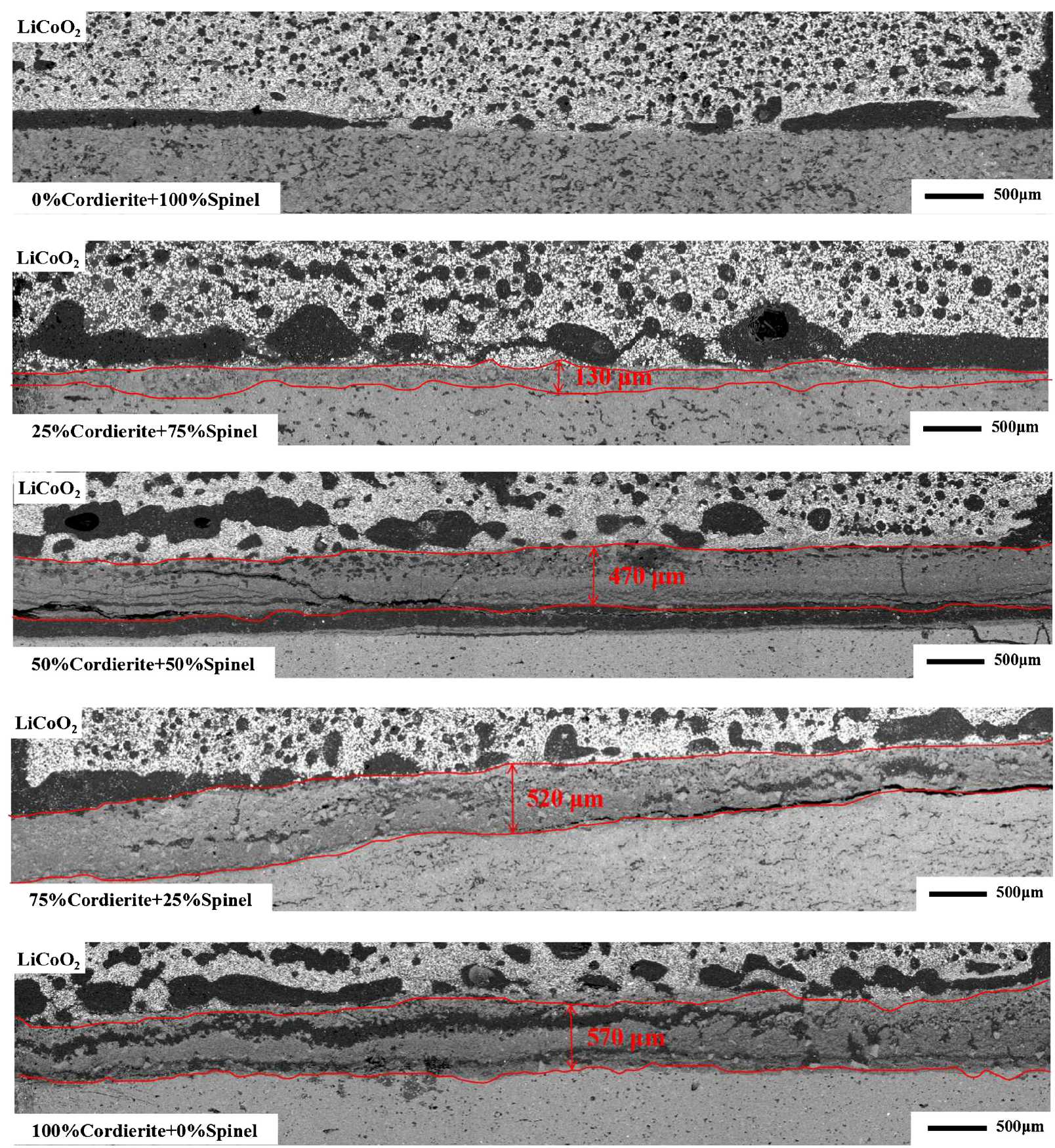

Fig. 5. The SEM images of cross-sectional region of samples after firing at $1000{ }^{\circ} \mathrm{C}$ for $3 \mathrm{~h}$. (a) $100 \mathrm{wt} \%$, (b) $75 \mathrm{wt} \%$ spinel $+25 \mathrm{wt} \%$ cordierite, (c) $50 \mathrm{wt} \%$ spinel $+50 \mathrm{wt} \%$ cordierite, (d) $25 \mathrm{wt} \%$ spinel $+75 \mathrm{wt} \%$ cordierite, (e) $100 \mathrm{wt} \%$ cordierite.

indicated that $\mathrm{LiAlO}_{2}$ did not react (or reacted a little) with cathode material. While for the cordierite, and the possible way of cathode material reacted with cordierite is as follows [as shown in Fig. 10(b)]: (1) $\mathrm{Li}^{+}$reacted with cordierite to generate $\mathrm{LiAlSiO}_{4}, \mathrm{Li}_{4} \mathrm{SiO}_{4}$ and $\mathrm{LiAlO}_{2}$ [Eq. (5)], the formation of $\mathrm{LiAlO}_{2}$ is too small and dispersed to form a core-shell structure to prevent the reaction from occurring; (2) meanwhile, $\mathrm{Li}_{4} \mathrm{SiO}_{4}$ existed as liquid phase at temperature higher than $730^{\circ} \mathrm{C}$, and the presence of the liquid phase provided a way for substance transformation, increasing the driving force of reaction and promoting the further reaction; (3) $\mathrm{LiAlSiO}_{4}$ and $\mathrm{Li}_{4} \mathrm{SiO}_{4}$ diffused into the interior along the pores under the capillary force; (4) $\mathrm{LiAlSiO}_{4}$ is a material with negative coefficient of thermal expansion $\left(a\right.$-axes and $c$-axes are $7.8 \times 10^{-6}{ }^{\circ} \mathrm{C}^{-1}$ and $-17.5 \times 10^{-6}{ }^{\circ} \mathrm{C}^{-1}$, respectively). ${ }^{21), 22)}$ In the cooling process, compressive stress generated due to the overall shrinkage of the sample, and the tension stress generated due to the expansion of $\mathrm{LiAlSiO}_{4}$ in the micropore, which may eventually lead to the spall of the samples.

\section{Conclusion}

In the paper, corundum-cordierite-spinel sagger materials were prepared, and the mechanical properties, thermal 

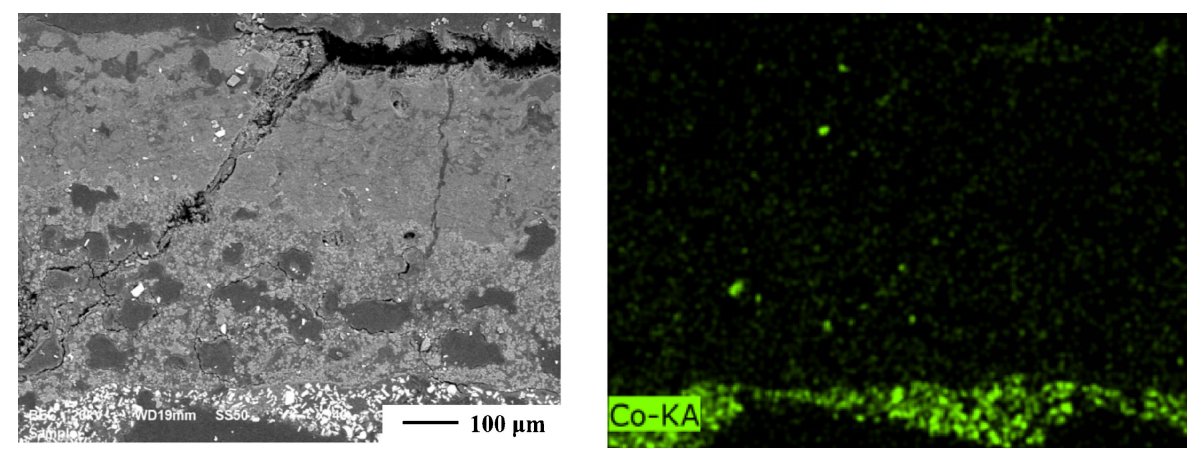

Fig. 6. EDS of sample with $0 \mathrm{wt} \%$ spinel after firing at $1000^{\circ} \mathrm{C}$ for $3 \mathrm{~h}$.

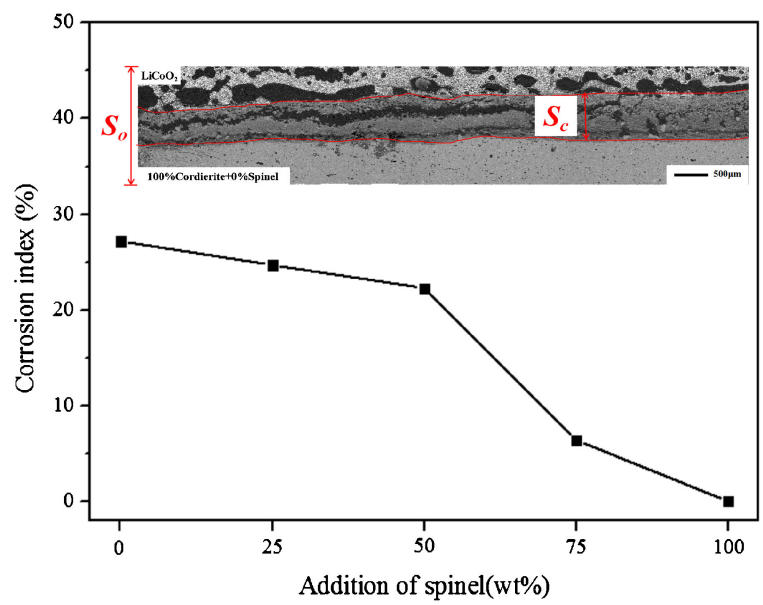

Fig. 7. The corrosion index of the samples corroded for $3 \mathrm{~h}$ at $1000^{\circ} \mathrm{C}$.

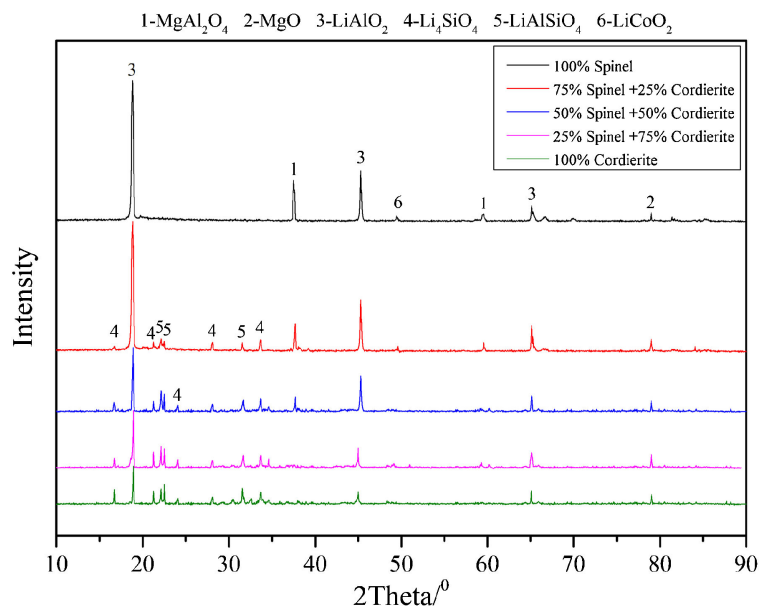

Fig. 8. XRD pattern of corrosion product after corroding at $1000^{\circ} \mathrm{C}$ for $3 \mathrm{~h}$.

shock resistance and corrosion resistance were investigated. The following conclusion could be drawn based on the results in the experiment.

(1) The materials containing spinel in situ $\mathrm{LiAlO}_{2}$ as a corrosion barrier between LIB cathode material and refractory components and physically separated the contact of LIB cathode materials with refractories, thereby improving the corrosion resistance of sagger material to LNCM mate-
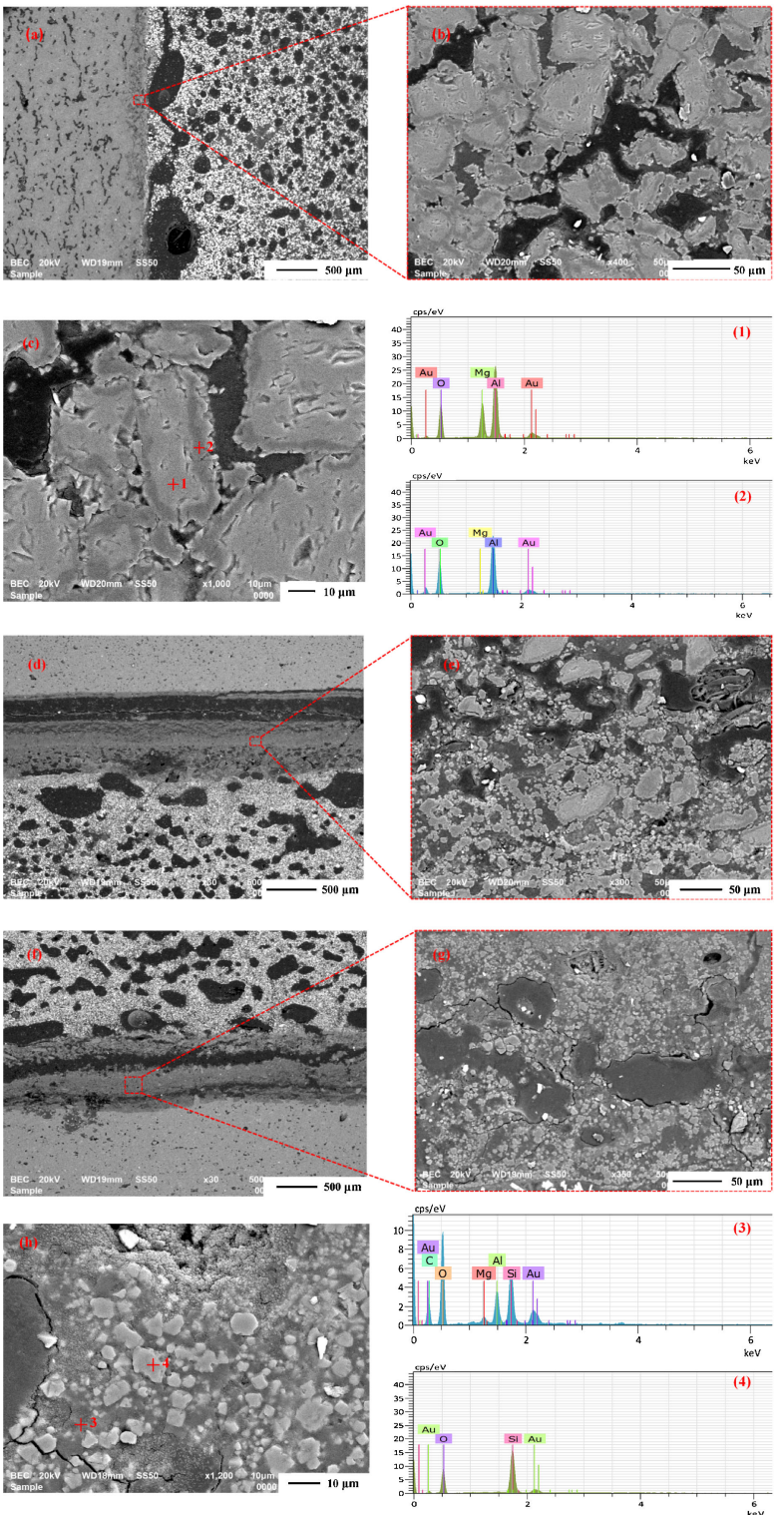

Fig. 9. Microstructure of the samples with different compositions after corroding at $1000^{\circ} \mathrm{C}$ for $3 \mathrm{~h}$. (a), (b) and (c) are the microstructure of sample with $100 \mathrm{wt} \%$ spinel,(d) and (e) are the microstructure of sample with $50 \mathrm{wt} \%$ spinel, (f), (g) and (h) are the microstructure of sample with $0 \mathrm{wt} \%$ spinel. 
Table 4. Compositions of the spot (\%)

\begin{tabular}{ccccc}
\hline & $\mathrm{Mg}$ & $\mathrm{Al}$ & $\mathrm{Si}$ & $\mathrm{O}$ \\
\hline 1 & 14.91 & 30.39 & - & 54.70 \\
2 & - & 35.08 & - & 64.92 \\
3 & 2.37 & 15.57 & 15.15 & 66.91 \\
4 & - & - & 17.44 & 82.56 \\
\hline
\end{tabular}
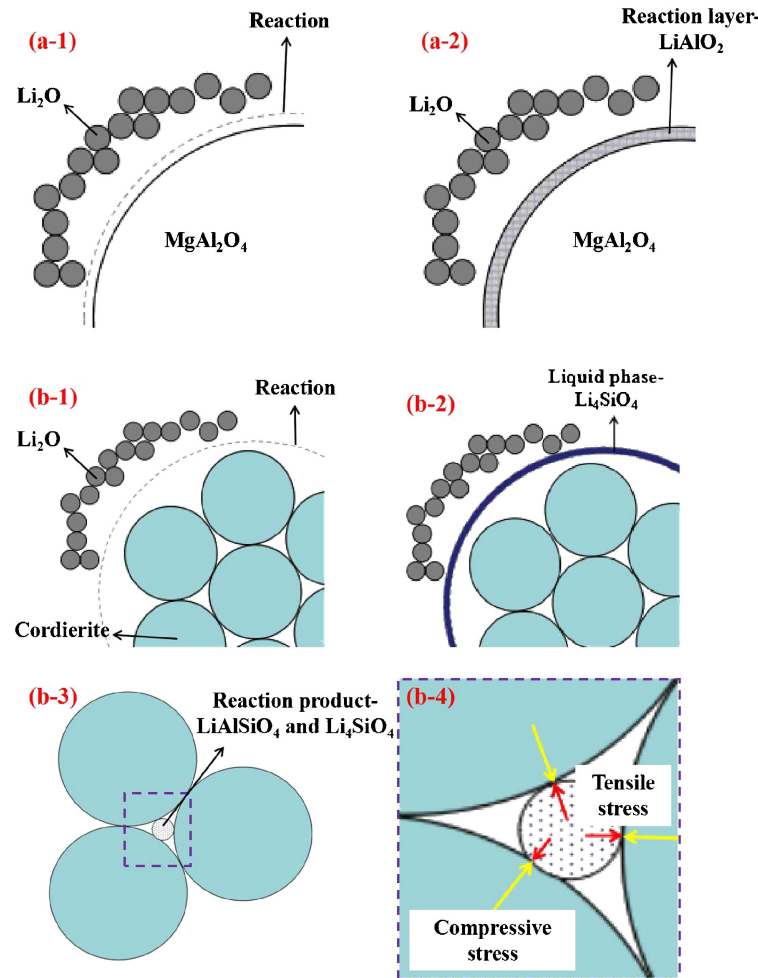

Fig. 10. Reaction diagram of raw material and cathode material. (a) spinel, (b) cordierite.

rial at elevated temperature, which could be applied with longer service life than traditional corundum-cordierite sagger material in calcining LIB material.

(2) The spinel-containing samples showed better thermal shock resistance due to the appropriate microcracks generation by mismatch thermal expansion between spinel and cordierite.

(3) The mechanical strength of samples improved by introducing spinel, due to the development of toughening mechanisms such as crack defection and bridging by the spinel with high mechanical strength acting as a second phase.

\section{References}

1) W.D. Li, B. Song and A. Manthiram, Chem. Soc. Rev., 46, 3006-3059 (2017).

2) Y. Jin, B. Zhu, Z.D. Lu, N. Liu and J. Zhu, Adv. Energy Mater., 7, 1700715 (2017).

3) P. Zhai, L. Chen, Y. Yin, S. Li, D. Ding and G. Ye, J. Australas. Ceram. Soc., 38, 2145-2151 (2018).

4) P. Zhai, L. Chen, S. Hu, X. Zhang, D. Ding, H. Li, S. Li, L. Zhu and G. Ye, Int. J. Appl. Ceram. Tec., 16, 287293 (2018).

5) D. F. Ding, G. T. Ye and C. G. Liu, Corros. Sci., 157, 324-330 (2019).

6) F. George, T. Kuo, Z. F. Wang, C. Z. Cheng and T. P. Kumar, J. Power Sources, 146, 245-249 (2006).

7) H. Liu, C. Y. Du, G. P. Yin, B. Song, P. J. Zuo and X. Q. Cheng, J. Mater. Chem. A, 2, 15640 (2014).

8) D. D. Liang, H. F. Xiang and X. Liang, RSC Adv., 7, 6809-6817 (2017).

9) J. Q. Zhao, S. Ellis, Z. Q. Xie and Y. Wang, ChemElectroChem., 11, 1821-1829 (2015).

10) A. Ouali, F. Sahnoune, M. Heraz and H. Belhouchet, Mol. Cryst. Liq. Cryst., 628, 65-71 (2016).

11) G. P. Liu, X. J. Jin, W. D. Qiu, G. Z. Ruan and Y. Y. Li, Ceram. Int., 42, 4941-4951 (2016).

12) M. A. L. Braulio, M. Rigaud, A. Buhr, C. Parr and V. C. Pandolfelli, Ceram. Int., 37, 1705-1724 (2011).

13) G. L. Nie, Y. W. Bao, D. T. Wan and Y. Tian, Key Eng. Mat., 768, 24-30 (2018).

14) Y. C. Ko, Ceram. Int., 28, 805-810 (2002).

15) X. H. Xu, Y. F. Zhang, J. F. Wu, C. Hu, C. L. Lu and D. Wang, Ceram. Int., 42, 17503-17512 (2016).

16) D. P. H. Hasselman, J. Am. Ceram. Soc., 52, 600-604 (1969).

17) M. A. Camerucci, G. Urretavizcaya, M. S. Castro and A. L. Cavalieria, J. Eur. Ceram. Soc., 21, 2917-2923 (2001).

18) G. Fiquet, P. Richet and G. Montagnac, Phys. Chem. Miner., 27, 103-111 (1999).

19) J. Wu, G. H. Leng, X. H. Xu, B. Z. Fang, Y. X. Zhang and K. Li, J. Chin. Ceram. Soc., 7, 962-969 (2012).

20) H. Huang, Z. H. Huang, M. H. Fang, Y. G. Liu and B. Jiang, Bull. Chin. Ceram. Soc., 30, 515-518 (2011).

21) H. Schulz, J. Am. Ceram. Soc., 57, 313-318 (1974).

22) A. V. Knyazev, D. N. Demidov and S. S. Knyazeva, Inorg. Mater., 53, 190-199 (2017). 